\title{
Performance Evaluation of Equipment Teaching Support Based on $C^{2} G S^{2}$ Model
}

\author{
Ling Li, Guangzhen Cui ${ }^{*}$, Xuliang Lv, Jianghua Hu, and Xiaodong Sun \\ College of Field Engineering, Army Engineering University of PLA, Nanjing 210000, China \\ *cgzovezy@163.com
}

Keywords: performance evaluation; equipment teaching support; DEA; $\mathrm{C}^{2} \mathrm{GS}^{2}$ model; efficiency

Abstract: In order to measure the comprehensive level and quality of colleges and universities, the $\mathrm{C}^{2} \mathrm{GS}^{2}$ quality control model is applied to evaluate the system of equipment teaching support in this paper. The features of teaching equipment support is analyzed and the input goal and output goal system are established. The experiment results show that about $40 \%$ of the sample equipment teaching support in DEA are non-technical effective state, so it is necessary to improve equipment support effectiveness and equipment maintenance and repair funds. Scientific evaluation and accounting of equipment support are conducive to the rational allocation of resources and the maximum utilization efficiency of equipment.

\section{Introduction}

Under the conditions of modern education and technology, colleges and universities have become the key to training outstanding talents. To measure the quality of education and personnel training model, the most basic is the construction of teaching equipment. The application of equipment teaching can not be separated from the protection, so that the teaching work of institutions put forward higher requirements for the construction of teaching and teaching support. To study the effectiveness of equipment teaching support, DEA (Data Envelopment Analysis) is a cross-domain relative efficiency evaluation method involving mathematics, operations research, mathematical economics, and management science. In literature [1], C2R model was established by analyzing the characteristics of equipment teaching support, but the paper did not analyze the pros and cons of each unit in depth. Reference [2] used the capability vector decomposition method and the analytic hierarchy process (AHP) modeling assumptions to model the equipment support system. However, the equipment support system performance evaluation is an extremely large and complicated system engineering. Some of the issues such as weights have yet to be further addressed [3].

This paper uses the C2GS2 model in the DEA model to evaluate the equipment teaching support of universities in recent years, the input goal and output goal system are established, and reasonably the impact of various elements of the teaching support is analyzed. It is instructive to improve the teaching effectiveness of military universities. 


\section{DEA-C $\mathrm{GS}^{2}$ Control Model}

There are $\mathrm{n}$ decision making units (DMU) in CCR model [4]. Each DMU has $\mathrm{m}$ inputs (indicating the unit's consumption of resources) and $\mathrm{s}$ outputs (indicating that the unit consumes resources), which are given in figure $1, x_{i j}$ is the ith input amount to the jth DMU, $x_{i j}>0 ; y_{i j}$ is the ith output to the jth DMU, $y_{i j}>0 ; v_{i}$ is the measure to the ith input; $u_{r}$ is the measure to the rth output, $i=1,2, \ldots ., m ; j=1,2, \ldots ., n ; r=1,2, \ldots ., s$.

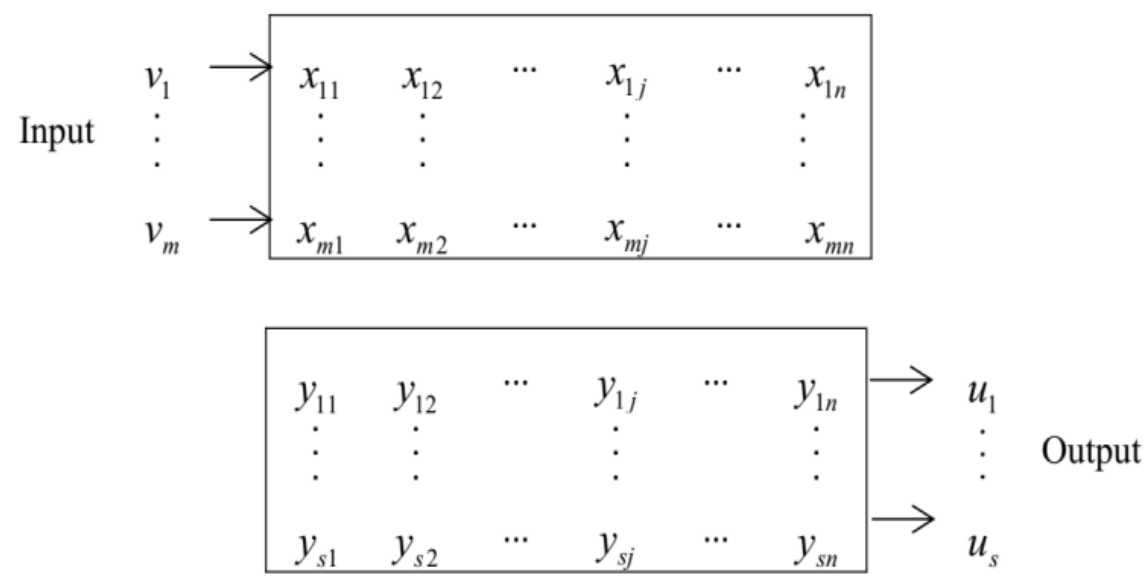

Fig.1 Input and Output of n DMU

The $\mathrm{C}^{2} \mathrm{R}$ model is generally used to evaluate the overall effectiveness of the scale efficiency and technical efficiency, while the $\mathrm{C}^{2} \mathrm{GS}^{2}$ model is only used to evaluate the technical effectiveness of the DMU [5,6]. It can be judged whether a certain decision unit is DEA effective through the $C^{2} \mathrm{R}$ model. If it is DEA effective, it can be confirmed that the production and operation is in a technically effective and scale effective state simultaneously. However, if the DMU is non-DEA valid, it can not be further judged whether it is technically valid. In order to use the dual linear programming to determine the decision unit $\mathrm{j}_{0}$, we introduce positive and negative deviation variables, named $\mathrm{S}_{0}^{+}$and $\mathrm{S}_{0}^{-}$, respectively. $\mathrm{C}^{2} \mathrm{GS}^{2}$ model is established in the follow equal.

$$
\left\{\begin{array}{l}
\min \left[\theta-\varepsilon\left(\hat{e}^{T} S^{-}+e^{T} S^{+}\right)\right] \\
\sum_{j=1}^{n} X_{j} \lambda_{j}+S^{-}=\theta X_{0} \\
\sum_{j=1}^{n} Y_{j} \lambda_{j}-S^{+}=Y_{0} \\
\sum_{j=1}^{n} \lambda_{j}=1, \quad \lambda_{j} \geq 0, j=1,2, \ldots ., n \\
S^{+} \geq 0, S^{-} \geq 0
\end{array}\right.
$$

The DMU efficiency calculated by this model is a pure technical efficiency, which reflects the pure technical benefits of the DMU. The optimal solution for the model is: $\theta_{0}, \lambda_{0}, \mathrm{~S}_{0}^{+}, \mathrm{S}_{0}^{-}$. Its evaluation criteria are as follows.

(1) If the optimal value $\theta_{0}=1$, and $\mathrm{S}_{0}^{+} \neq 0$ or $\mathrm{S}_{0}^{-} \neq 0$, the DMU is weak DEA valid;

(2) If the optimal value $\theta_{0}=1$, and $\mathrm{S}_{0}^{+}=0$ or $\mathrm{S}_{0}^{-}=0$, the DMU is DEA valid.

(3) If the optimal value is $\theta_{0}<1$, the DMU is DEA invalid. 


\section{Evaluation Index System}

For the construction of equipment teaching support in different years, the DEA-C ${ }^{2} \mathrm{SS}^{2}$ model is used in the article to analyze the level of equipment teaching and teaching effectiveness [7,8]. The basic idea of the effectiveness evaluation model for equipment teaching system in colleges is that the actual number of internship support personnel, the number of internship equipment, equipment maintenance funds, subsidies for outfielders and purchase of aviation materials for the same institution are taken as input indicators which are set to $\mathrm{x} 1, \mathrm{x} 2, \mathrm{x} 3, \mathrm{x} 4, \mathrm{x} 5$, respectively. The tasks of the internship guarantee including the number of internships for trainees, the total number of internships for internships, the availability of internship equipment, and the passing rate of trainees' internships, are taken as output indicators which are set to y1, y2, y3, y4, respectively. The specific flow chart is shown in fig 2.

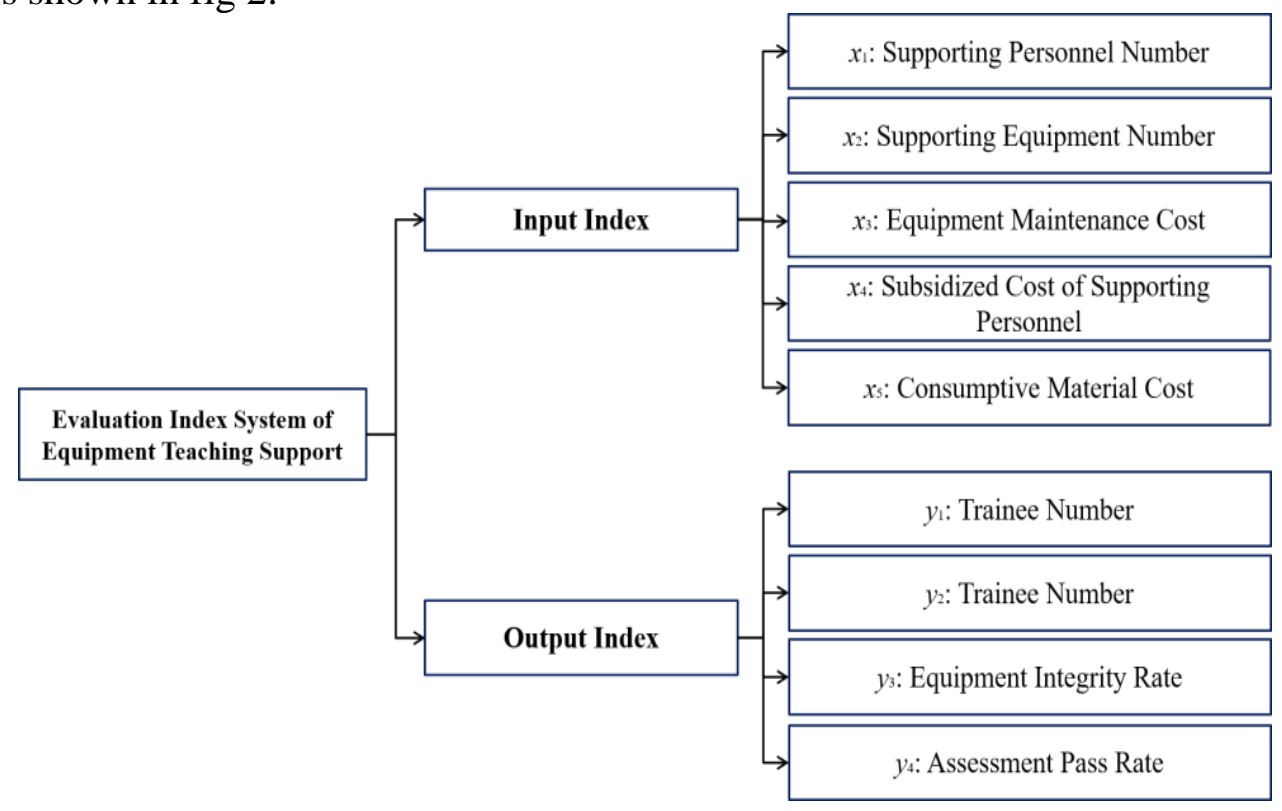

Fig.2 Evaluation Index System of Equipment Teaching Support

\section{Assessment of Equipment Teaching Support}

According to the teaching support of field equipment in the colleges and universities, the relevant data for the past ten years were selected for evaluation. Table 1 gives the specific data of the input indicators and output indicators of the teaching equipment. All the DMU are evaluated using the C2GS2 model by the matlab software programming.

From the overall point of view, as can be seen from Table 1, DMU3, DMU4, DMU6, DMU8, DMU9, DMU10 is DEA effective, that is, the teaching equipment support achieves the optimal combination state, the rest of the units are non-DEA effective, and there are different degrees of equipment support redundancy. I problem. Comparative analysis of DMU1 and DMU2, although there are fewer protection personnel in DMU1, due to the investment in equipment maintenance costs, the efficiency of protection is greatly improved. The order of the effectiveness is DMU4>DMU8>DMU3>DMU9>DMU10>DMU6>DMU5>DMU7>DMU1>DMU2 through the efficiency sorting. The DMU5 achieves maximum efficiency due to the higher cost and lower trainee number. The existence of positive and negative deviation variables in table 1 indicates that equipment support has not yet reached maximum efficiency, which still needs to be reasonably configured in the case of achieving high quality teaching. 
Table 1 Evaluation indicator data of equipment teaching support

\begin{tabular}{ccccccccccc}
\hline $\begin{array}{c}\mathrm{DMU} \\
i\end{array}$ & $\mathrm{DMU}_{1}$ & $\mathrm{DMU}_{2}$ & $\mathrm{DMU}_{3}$ & $\mathrm{DMU}_{4}$ & $\mathrm{DMU}_{5}$ & $\mathrm{DMU}_{6}$ & $\mathrm{DMU}_{7}$ & $\mathrm{DMU}_{8}$ & $\mathrm{DMU}_{9}$ & $\mathrm{DMU}_{10}$ \\
\hline$x_{1}$ & 78 & 67 & 72 & 70 & 65 & 52 & 58 & 61 & 66 & 73 \\
$x_{2}$ & 39 & 37 & 43 & 47 & 49 & 40 & 42 & 44 & 41 & 49 \\
$x_{3}$ & 109 & 95 & 125 & 145 & 102 & 115 & 120 & 140 & 130 & 130 \\
$x_{4}$ & 1.5 & 1.3 & 1.6 & 1.7 & 1.2 & 1.4 & 1.1 & 1.3 & 1.9 & 1.5 \\
$x_{5}$ & 35 & 48 & 45 & 40 & 28 & 40 & 35 & 40 & 43 & 39 \\
$y_{1}$ & 1353 & 1150 & 1429 & 1235 & 1090 & 1205 & 1459 & 1360 & 1263 & 1108 \\
$y_{2}$ & 3906 & 3432 & 4269 & 3768 & 3525 & 3868 & 4081 & 3965 & 3728 & 3598 \\
$y_{3}$ & 87 & 89 & 92 & 81 & 83 & 92 & 90 & 95 & 84 & 86 \\
$y_{4}$ & 95 & 96 & 94 & 99 & 94 & 96 & 95 & 98 & 96 & 97 \\
$S_{1}{ }^{-}$ & 0.0723 & 0.1892 & 0.0973 & 0.0828 & 0.0000 & 0.1443 & 0.0501 & 0.0821 & 0.1593 & 0.1818 \\
$S_{2}{ }^{-}$ & 0.0498 & 0.2599 & 0.0825 & 0.0594 & 0.1340 & 0.1702 & 0.0900 & 0.2441 & 0.1638 & 0.2604 \\
$S_{3}{ }^{-}$ & 0.2498 & 0.3075 & 0.1910 & 0.0747 & 0.0872 & 0.1945 & 0.1972 & 0.0521 & 0.0857 & 0.0810 \\
$S_{4}{ }^{-}$ & 0.2748 & 0.2825 & 0.1510 & 0.0294 & 0.1494 & 0.1987 & 0.1791 & 0.0316 & 0.1820 & 0.0937 \\
$S_{5}{ }^{+}$ & 0.0598 & 0.1909 & 0.1377 & 0.0033 & 0.2076 & 0.0908 & 0.2126 & 0.2141 & 0.1529 & 0.0906 \\
$S_{1}{ }^{+}$ & 0.1941 & 0.2460 & 0.1883 & 0.1861 & 0.0793 & 0.1729 & 0.1021 & 0.1828 & 0.1309 & 0.0847 \\
$S_{2}{ }^{+}$ & 0.3276 & 0.2887 & 0.0406 & 0.0000 & 0.1532 & 0.1481 & 0.2247 & 0.1521 & 0.0024 & 0.1450 \\
$S_{3}{ }^{+}$ & 0.0504 & 0.3067 & 0.0973 & 0.1047 & 0.1755 & 0.1605 & 0.2006 & 0.0616 & 0.1053 & 0.1890 \\
$S_{4}{ }^{+}$ & 0.0526 & 0.1094 & 0.0410 & 0.0828 & 0.1605 & 0.0981 & 0.1077 & 0.1328 & 0.0262 & 0.1606 \\
$\xi_{j}{ }^{*}$ & 1.05 & 1.25 & 1 & 1 & 1.36 & 1.18 & 1.23 & 1 & 1 & 1 \\
$\boldsymbol{\theta}$ & 1.126 & 1.173 & 0.906 & 0.821 & 1.034 & 0.999 & 1.921 & 0.882 & 0.924 & 0.967 \\
ranks & 9 & 10 & 3 & 1 & 7 & 6 & 8 & 2 & 4 & 5 \\
\hline
\end{tabular}

\section{Conclusion}

The construction of equipment teaching support in colleges is an important part of the equipment support system and the quality of education. The purpose of this article is to use limited resources and maximize its effectiveness by using the $\mathrm{C}^{2} \mathrm{GS}^{2}$ model in the DEA method to analyze the effectiveness of college equipment teaching support. The results show that improving equipment support effectiveness and investing in equipment maintenance and repair funds are of the highest priority. In addition, the supporting personnel and off-site auxiliary equipment are also important factors that affect equipment teaching and training. Scientific evaluation and accounting of equipment support are conducive to the rational allocation of resources and the maximum utilization efficiency of equipment.

\section{Acknowledgement}

This work is supported by China Post-Doctoral Fund (Grand No.2015M572730) and Defense Science and Technology Fund (Grand No.3602043).

\section{References}

[1] Liao Dongmin, Xu Jihui, Xu Zhengang. DEA-based efficiency evaluation on equipment teaching support of academies[J]. Experimental Technology and Management. 2011,28(5):202-204.

[2] Tan Jin, Luo Zhengying, Xu Guangwei. Evaluation on input performance of technological innovation based on CCR, BCC and SE-DEA models [J]. Science and Technology and Economy. 2017,30(1):36-40.

[3] Li Rongping, Wu Jingru. Evaluation and analysis to regional enterprise technology innovation effectiveness based on DEA [C]. 2009 International Conference on Machine Learning and Cybernetics. 2009:2543-2548.

[4] Alearaz J, Rarnon N, Ruiz J et a1. Ranking ranges in cross-efficiency evaluations [J]. European Journal of Operational Research. 2013,22(3):516-521. 
[5] Contreras I. Optimizing the rank position of the DMLT as secondary goal in DEA cross-evaluation [J]. Applied Mathematical Modelling. 2012,36(6):22-26.

[6] Wang Yingming. A linear programming approximation to the eigenvector method in the analytic hierarchy process[J]. Information Sciences, 2011(181):5240-5248.

[7] Wu Jie, Hang Lang. DEA game cross efficiency approach to olympic rankings[J]. Omega. 2009, 37(4):909-918.

[8] Su Haitao, Ma Xiaowei, Shen Maohu. Research of efficiency methods of quality control based on the DEA [J]. Industrial technology \& economy. 2008,27(10):86-88. 